\title{
Long-term effect of imiglucerase in Latin American children with Gaucher disease type 1: lessons from the International Collaborative Gaucher Group Gaucher Registry
}

Jose Simon Camelo $\mathrm{Jr}^{1+}$, Juan Francisco Cabello², Guillermo G Drelichman ${ }^{3}$, Marcelo M Kerstenetzky ${ }^{4}$, Isabel C Sarmiento ${ }^{5}$, Soledad Suarez Ordoñez ${ }^{6}$, John S Taylor ${ }^{7}$, Andrea R Gwosdow ${ }^{8}$ and Adriana Linares ${ }^{9^{* \dagger}}$

\begin{abstract}
Background: The clinical characteristics of Latin American children enrolled in the International Collaborative Gaucher Group Gaucher Registry at the time of first enzyme therapy infusion (baseline) were investigated, with special emphasis on long-term outcomes.

Methods: Inclusion criteria were all Latin American patients with Gaucher disease type 1 who were $<18$ years at start of imiglucerase (Genzyme) or alglucerase (Genzyme) therapy. Patients were stratified based on whether they had a confirmed diagnosis of glucocerebrosidase deficiency and clinical findings of anemia, thrombocytopenia, hepatomegaly, splenomegaly, bone disease and/or growth retardation at baseline. Patients were evaluated only if they had at least one follow-up for a given parameter. Data were analyzed using nonlinear mixed models.

Results: As of October 2011, 443 patients met inclusion criteria. At diagnosis $(n=443)$ some children presented with anemia (189/353), thrombocytopenia (199/339), bone pain (88/248) and bone crises (30/242), while most children reported splenomegaly (volumetric: 55/57; palpation: 204/221), hepatomegaly (volumetric: 32/37; palpation: 204/230), and radiological evidence of bone disease (107/149). Of those children symptomatic at baseline, 174 had anemia, 184 had thrombocytopenia and 129 had mean height Z-scores of $<-2.0$. Volumetric evaluations indicate hepatomegaly and splenomegaly. After 8 years of treatment, children showed improvements in mean hemoglobin levels, platelet count, liver and spleen volumes, growth, bone pain and bone crises.
\end{abstract}

Conclusion: Continuous and long-term treatment with imiglucerase improves hematological, visceral and skeletal manifestations of Gaucher disease type 1.

Trial registration: NCT00358943.

Keywords: Imiglucerase, Children, Gaucher disease type 1, Long-term outcomes, Hematological, Organomegaly

\section{Background}

Gaucher disease (GD), one of the most common lysosomal storage diseases, is an autosomal recessive condition caused by the deficiency of glucocerebrosidase (EC 3.2.1.45; lysosomal glucocerebrosidase), a lysosomal enzyme that hydrolyzes glucocerebroside, an intermediate

\footnotetext{
*Correspondence: talinaresb@unal.edu.co

${ }^{\dagger}$ Equal contributors

${ }^{9}$ Pediatrics, Universidad Nacional de Colombia, Calle 50 8-24 of 401, Bogotá, Colombia

Full list of author information is available at the end of the article
}

in glycolipid metabolism $[1,2]$. This deficiency results in the accumulation of glucocerebrosides within cells of the macrophage-monocyte system, particularly those of the spleen, liver, kidneys, lungs, brain and bone marrow.

Three common clinical subtypes of GD are recognized: types 1,2 and 3 [2,3]. Type 1 (GD1; non-neuropathic) is the most common, occurring in approximately 1 in 50,000 live births and more often among persons of Ashkenazi Jewish heritage [4]. Type 2 (acute neuronopathic) and type 3 (chronic neuronopathic) are less common and are characterized by neurological involvement [2-6]. 
GD1 comprises over 90\% of all GD cases [7] and is characterized by growth retardation $[6,8]$, delayed puberty [9], organomegaly (liver, spleen) [8], bone involvement resulting from marrow infiltration, anemia and thrombocytopenia [6-8]. Although symptomatic disease could develop at any age, reports show that $48 \%$ of patients with GD are diagnosed as children, before 6 years of age [6]. In Latin America, nearly half (47\%) of the patients were diagnosed before 10 years of age [10]. The course of GD1 is more likely to be severe when signs and symptoms are seen in young children [6].

Treatment for GD is focused on the reduction of stored glucocerebroside by replacing glucocerebrosidase with a recombinant active form of the enzyme (imiglucerase or alglucerase; Genzyme, a Sanofi company, Cambridge, Massachusetts, United States of America [USA]). Currently, enzyme therapy is administered via regular intravenous infusions. Imiglucerase and alglucerase have been shown to be therapeutically equivalent treatments [11]. In this paper, the term imiglucerase will be used to denote patients who received either alglucerase or imiglucerase.

Enzyme therapy with imiglucerase is safe and effective in reducing the systemic manifestations of GD1 [5,11-15], but the response to therapy in terms of time course can vary between individuals [12]. Andersson et al. [14] evaluated the outcome of 884 children who received long-term enzyme therapy with imiglucerase and found a substantial improvement in most of the clinical and biochemical manifestations [14].

The current study extends these previous reports $[6,14]$ and focuses on pediatric patients in Latin America. This group of Latin American children represents one of the largest populations of GD1 patients studied to date.

\section{Methods \\ ICGG gaucher registry}

All data reported in this study were obtained from the ICGG Gaucher Registry as of 7 October 2011. The ICGG Gaucher Registry is an ongoing, observational database that tracks the natural history and outcomes of patients with GD, regardless of symptoms or treatment. Historically, each independent site has been responsible for determining whether site specific Institutional Review Board or Ethics Committee (IRB/EC) review is required for participation in the ICGG Gaucher Registry in accordance with institutional policies and local laws and regulations. As of January 2013, the ICGG Gaucher Registry protocol has required sites to submit to an IRB/EC. Treating physicians determine the frequency of assessments according to a patient's individualized need for medical care and routine follow-up.

\section{Study population}

All Latin American patients with GD1 in the ICGG Gaucher Registry as of 7 October 2011 who were $<18$ years of age at the start of alglucerase (Ceredase ${ }^{\bullet}$, Genzyme) or imiglucerase (Cerezyme ${ }^{\circ}$, Genzyme) therapy were analyzed in this study (NCT00358943) (Table 1). Of the eligible patients, subsets were classified based on clinical diagnosis of anemia, thrombocytopenia, qualitative and volumetric evaluations of hepatomegaly and splenomegaly, bone pain, bone crisis, skeletal characteristics and/or growth retardation at baseline. Baseline was defined using a window for all time points before first infusion through 2 weeks after first infusion. Data were analyzed to determine the effect of imiglucerase treatment in children stratified by severity of disease. Each variable was studied independently using the definitions indicated below.

GD was diagnosed on the basis of deficient glucocerebrosidase enzyme activity; deoxyribonucleic acid mutation analyses are optional. Genotypes were analyzed by the Molecular Development Laboratory at the University of Washington (Seattle, WA, USA) and the data were provided to the ICGG Gaucher Registry, maintaining full patient confidentiality. The designation of each patient to a specific type of GD was done by the reporting physician.

\section{Study variables}

All the variables under evaluation were assessed and reported based on years on imiglucerase therapy: baseline, 0 to $\leq 1 ;>1$ to $\leq 2 ;>2$ to $\leq 3 ;>3$ to $\leq 4 ;>4$ to $\leq 5 ;>5$ to $\leq 6 ;>6$ to $\leq 7$; and $>7$ to $\leq 8$ years.

\section{Hemoglobin levels}

Hemoglobin levels were reported as gram/deciliter (g/dL). Anemia was defined according to age and gender norms for hemoglobin concentrations (detailed in Table 2).

\section{Platelet counts}

Platelet counts were reported as number of platelets $\times 10^{9}$ / Liter (L) (see Table 2 for category definitions).

\section{Liver and spleen volumes}

Liver and spleen volumes were measured clinically by palpation and/or volumetrically by either ultrasonography, magnetic resonance imaging, or computed tomography and reported as multiples of normal (MN) size predicted for body weight as previously reported [16]. A standard formula [17] was used to convert USA measurements to volume equivalents (see Table 2 for category definitions). Qualitative reports of visceromegaly by palpation were reported to the ICGG Gaucher Registry by physicians who answered "yes" or "no" questions regarding the presence or absence of hepatomegaly or splenomegaly. 
Table 1 Characteristics of all Latin American pediatric ${ }^{a}$ type 1 Gaucher patients

\begin{tabular}{|c|c|}
\hline Patients enrolled & $N=443$ \\
\hline Gender, n (\%) & $n=443$ \\
\hline Male & $201(45.4)$ \\
\hline Female & $242(54.6)$ \\
\hline Genotype $^{b}, \mathrm{n}(\%)$ & $n=224$ \\
\hline N370S/Rare allele ${ }^{c}$ & $69(31)$ \\
\hline N370S/L444P & $56(25)$ \\
\hline $\mathrm{N} 370 \mathrm{~S} / ?^{\mathrm{d}}$ & $30(13)$ \\
\hline$\left\llcorner 444 \mathrm{P} / ?^{\mathrm{d}}\right.$ & $14(6)$ \\
\hline Rare allele ${ }^{c} /$ rare allele ${ }^{c}$ & $13(6)$ \\
\hline N370S/IVS2 + 1 & $8(4)$ \\
\hline N370S/N370S & $7(3)$ \\
\hline L444P/rare allele ${ }^{c}$ & $7(3)$ \\
\hline N370S/84GG & $6(3)$ \\
\hline L444P/L444P & $4(2)$ \\
\hline Rare allele ${ }^{c} ?^{d}$ & $3(1)$ \\
\hline N370S/D409H & $2(1)$ \\
\hline D409H/rare allele ${ }^{c}$ & $2(1)$ \\
\hline$?^{d / ?^{d}}$ & $2(1)$ \\
\hline IVS2 + 1/rare allele ${ }^{c}$ & $1(<1)$ \\
\hline Age at diagnosis, n (\%) & $n=443$ \\
\hline $0^{\mathrm{a}}$ to $<6$ years & $190(43.8)$ \\
\hline 6 to $<12$ years & $173(40.1)$ \\
\hline 12 to $<18$ years & $70(16.1)$ \\
\hline
\end{tabular}

Treatment dose, mean \pm SD, U/kg/2wks

Baseline

After 8 years of imiglucerase

Age at first infusion, $\mathrm{n}(\%)$

0 to $<6$ years

6 to $<12$ years

12 to $<18$ years

Splenectomized patients, $\mathbf{n}(\%)$

Distribution by country, $\mathrm{n}$ (\%)

Brazil

Argentina

Colombia

Venezuela

Chile

Mexico

Others $^{e}$

Ethnicity, n (\%)

Black/Caribbean

Caucasian, non-Jewish

Hispanic
$43.4 \pm 16.61$

$36.8 \pm 12.37$

$n=443$

122 (27.5)

180 (40.6)

141 (31.8)

33 (7.4\%)

$\mathrm{n}=443$

272 (61.4)

78 (17.6)

$34(7.7)$

$32(7.2)$

$9(2.0)$

7 (1.6)

$11(2.5)$

$n=443$

$130(29.3)$

$121(27.3)$

116 (26.2)

Table 1 Characteristics of all Latin American pediatric ${ }^{a}$ type 1 Gaucher patients (Continued)

\begin{tabular}{|c|c|}
\hline Multi-ethnic, non-Jewish or Arab & $15(3.4)$ \\
\hline American Indian & $4(0.9)$ \\
\hline Jewish, Ashkenazi & $4(0.9)$ \\
\hline Other & $0(0.0)$ \\
\hline Unknown & $53(12.0)$ \\
\hline \multicolumn{2}{|c|}{ 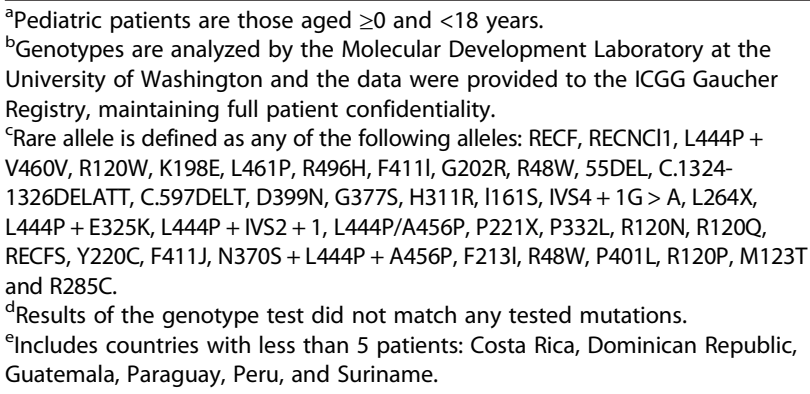 } \\
\hline
\end{tabular}

\section{Height Z-scores}

Individual patient height was compared with normal percentile values for age and gender using Centers for Disease Control and Prevention (Atlanta, GA, USA) growth charts [18], and age and gender-adjusted Z-scores were calculated.

\section{Bone pain}

Bone pain was defined as being present if the patient reported an event in the 30-day interval before the medical visit.

\section{Bone crises}

Bone crisis was defined as being present if the patient reported an event at the time of the medical visit (see Table 2 for definition).

\section{Statistical analyses}

All data are expressed as mean \pm standard deviation (SD), median with 25th and 75th percentiles, or frequency distribution, as appropriate. The numbers and percentages of patients with data available at each time point are reported. All data received before initiating enzyme therapy were considered baseline data.

Nonlinear mixed models were used to analyze the predicted time course for hemoglobin, platelet count, liver and spleen volumes, and height Z-score [19]. For liver and spleen volumes, only those volumes reported as MN were included in the nonlinear mixed models.

SAS (Statistical Software System version 9.2 - SAS Institute, Cary, NC, USA) was used to perform all data analysis in accordance with the guidelines for Strengthening the Reporting of Observational Studies in Epidemiology [20]. 
Table 2 Baseline ${ }^{a}$ clinical characteristics for all imiglucerase-treated Latin American pediatric patients with type 1 Gaucher disease

\begin{tabular}{|c|c|c|}
\hline Patients enrolled & 443 & \\
\hline Anemia $^{b}, \mathrm{n}(\%)$ & $N=353$ & \\
\hline Yes & $189(54)$ & \\
\hline No & $164(46)$ & \\
\hline $\begin{array}{l}\text { Thrombocytopeniac (Platelet } \\
\text { count, } \times 10^{9} / \mathrm{L} \text { ) [Non-splenectomized } \\
\text { patients only], } \mathrm{n}(\%)\end{array}$ & $N=339$ & \\
\hline Mild or none $(\geq 120)$ & $140(41)$ & \\
\hline Moderate $(60$ to <120) & $154(45)$ & \\
\hline Severe $(<60)$ & $45(13)$ & \\
\hline $\begin{array}{l}\text { Splenomegaly (Spleen volume in } \\
\text { multiples of normal [MN]), } n(\%)\end{array}$ & $n=57$ & \\
\hline Mild or None $(\leq 5)$ & $2(4)$ & \\
\hline Moderate (>5 to $\leq 15$ ) & $13(23)$ & \\
\hline Severe (>15) & $42(74)$ & \\
\hline $\begin{array}{l}\text { Qualitative splenomegaly }{ }^{d} \\
\text { (Palpation), n (\%) }\end{array}$ & $n=221$ & \\
\hline Yes & $204(96.7)$ & \\
\hline No & $7(3.3)$ & \\
\hline $\begin{array}{l}\text { Hepatomegaly (Liver } \\
\text { volume in MN), } n(\%)\end{array}$ & $n=37$ & \\
\hline Mild or None $(\leq 1.25)$ & $5(14)$ & \\
\hline Moderate $(>1.25$ to $\leq 2.5)$ & $26(70)$ & \\
\hline Severe $(>2.5)$ & $6(16)$ & \\
\hline $\begin{array}{l}\text { Qualitative hepatomegaly } \\
\text { (Palpation), } \mathrm{n}(\%)\end{array}$ & $n=230$ & \\
\hline Yes & $204(88.7)$ & \\
\hline No & $26(11.3)$ & \\
\hline Bone pain, $n(\%)$ & $n=248$ & \\
\hline Absent & $160(65)$ & \\
\hline Present & $88(35)$ & \\
\hline Prior bone crisis, n (\%) & $n=242$ & \\
\hline Absent & $212(88)$ & \\
\hline Present & $30(12)$ & \\
\hline $\begin{array}{l}\text { Radiologic bone disease, } \mathrm{n}(\%) \\
\text { (Evidence of any bone disease) }\end{array}$ & $n=149$ & \\
\hline Absent & $42(28)$ & \\
\hline Present & $107(72)$ & \\
\hline Type of bone disease reported & $\begin{array}{l}\text { Any data } \\
\text { available, } \mathrm{n}\end{array}$ & $\begin{array}{l}\text { Abnormality } \\
\text { present, } \mathrm{n}(\%)\end{array}$ \\
\hline Avascular necrosis & 103 & $20(19)$ \\
\hline Erlenmeyer flask deformity & 110 & $65(59)$ \\
\hline Fractures & 81 & $2(2)$ \\
\hline Infarction & 97 & $22(23)$ \\
\hline
\end{tabular}

Table 2 Baseline ${ }^{a}$ clinical characteristics for all imiglucerase-treated Latin American pediatric patients with type 1 Gaucher disease (Continued)

\begin{tabular}{|c|c|c|}
\hline Lytic lesions & 99 & $20(20)$ \\
\hline Marrow infiltrations & 75 & $56(75)$ \\
\hline Osteopenia & 98 & $56(57)$ \\
\hline $\begin{array}{l}\text { Decreased bone mineral density } \\
\text { (Lumbar spine dual energy x-ray } \\
\text { absorptiometry Z-score }), \mathrm{n}(\%)\end{array}$ & $n=19$ & \\
\hline Mild or None $(\leq-1)$ & $6(32)$ & \\
\hline Moderate $(>-2.5$ to $\leq-1)$ & $9(47)$ & \\
\hline Severe $(>-2.5)$ & $4(21)$ & \\
\hline Pediatric growth retardation, $\mathrm{n}(\%)$ & $n=225$ & \\
\hline Observed & $102(45)$ & \\
\hline Expected $^{f}$ & $11(5)$ & \\
\hline
\end{tabular}

a'Baseline' is defined as the data point closest to the first infusion date, at all time prior to first infusion through 2 weeks (inclusive) following first infusion. Patients with no infusion date were excluded from the analysis for each hematological, visceral and bone assessment.

${ }^{\mathrm{b}}$ Anemia is defined according to age and gender norms for hemoglobin concentrations as follows: $<12 \mathrm{~g} / \mathrm{dL}$ for males older than 12 years; $<11 \mathrm{~g} / \mathrm{dL}$ for females older than 12 years; $<10.5 \mathrm{~g} / \mathrm{dL}$ for children ages $>2$ to 12 years; $<9.5 \mathrm{~g} / \mathrm{dL}$ for children ages 6 months to 2 years; $<10.1 \mathrm{~g} / \mathrm{dL}$ for children younger than 6 months of age.

'Among the 12 partial or total splenectomy patients, thrombocytopenia was classified as mild or none in 11 (92\%), moderate in $1(8 \%)$, and severe in $0(0 \%)$. ${ }^{\mathrm{d}}$ Qualitative splenomegaly and hepatomegaly are determined by palpation on the basis of a yes/no response.

${ }^{\text {e}}$ Standard deviations of age and sex-adjusted norms.

${ }^{f}$ Pediatric growth retardation is defined as the number of patients who are below the 5 th percentile for height based on the age and gender of the normal healthy population and is calculated as $0.05 \mathrm{X}$ the total number of patients.

\section{Results}

As of 7 October 2011, 6,044 patients were enrolled in the ICGG Gaucher Registry. Of these, 1,540 patients had a diagnosis of GD1 and initiated imiglucerase treatment before 18 years of age. The number of patients from Latin America who met these inclusion criteria was 443. The final analysis was based on these 443 patients.

\section{Demographics and genotypes of all Latin American children with GD1}

The demographic characteristics of the Latin American pediatric population are summarized in Table 1. Most $(83.9 \%, n=363)$ were diagnosed with GD1 before 12 years of age. Most (61.4\%) children were from Brazil, with Black/Caribbean (29.3\%), non-Jewish Caucasian (27.3\%) or Hispanic (26.2\%) ancestry. Most patients $(40.6 \%, \mathrm{n}=180)$ initiated treatment between 6 and $<12$ years of age.

Genotypes were reported for approximately half $(n=224)$ of the children (Table 1$)$. The majority (80\%) had at least one N370S allele, with the most common genotypes being N370S/Rare Allele (69 out of 224 patients), N370S/L444P (56 out of 224 patients) or N370S/? (30 out of 224 patients).

At baseline, the mean dose $( \pm \mathrm{SD})$ of imiglucerase for the entire study population was $43.4 \pm 16.61 \mathrm{U} / \mathrm{kg} / 2 \mathrm{wks}$ 
(Table 1). Most patients were dosed in the ranges of either $>15$ to $\leq 45$ units $/ \mathrm{kg} / 2$ wks $(50 \%)$ or $>45$ to $\leq 90$ units $/ \mathrm{kg} / 2$ wks (47\%). After 8 years of therapy with imiglucerase, the mean dose $( \pm \mathrm{SD})$ was $36.8 \pm 12.37 \mathrm{U} / \mathrm{kg} /$ 2 wks; most (96\%) patients were still receiving doses in the middle range ( $>15$ to $\leq 45$ or $>45$ to $\leq 90$ units $/ \mathrm{kg} / 2 \mathrm{wks}$ ).

\section{Baseline values for Latin American children with GD1}

Hematological and visceral characteristics of the entire study population at baseline are shown in Table 2 . Anemia was present in 54\% (189 out of 353) of patients and 58\% (199 out of 339) had moderate to severe thrombocytopenia. Enlarged spleens were common at baseline with $96.7 \%$ (204 out of 211) exhibiting splenomegaly by palpation, and $97 \%$ with moderate to severe splenomegaly as indicated by volumetric spleen measurements $>5 \mathrm{MN}$. Enlarged livers were reported by both palpation (88.7\%, 204 out of 230) and by volumetric measurement as moderate to severe hepatomegaly in $86 \%$ (32 out of 37 ).

Bone disease was present in 72\% (107/149) (Table 2) with marrow infiltration, Erlenmeyer flask deformity and osteopenia reported most often. Growth retardation was reported in $45 \%(102 / 225)$. Bone pain and bone crisis were reported in 35\% (88/248) and 12\% (30/242), respectively.

\section{Long-term responses to imiglucerase among symptomatic Latin American children with GD1 at baseline}

For patients with GD1 manifestations at baseline, changes in hematological parameters (Figures 1 and 2), and visceral measurements (Figures 3 and 4), and height Z-scores (Figure 5) were reported yearly from baseline through 8 years of treatment.

At baseline, 174 patients were reported to have anemia (mean hemoglobin concentration of $9.2 \pm 1.29 \mathrm{~g} / \mathrm{dL}$ ) (Figure 1). After 1 year of treatment, mean hemoglobin concentration improved to $11.1 \pm 1.59 \mathrm{~g} / \mathrm{dL}$ and continued to improve through 8 years of treatment to $12.8 \pm$ $1.51 \mathrm{~g} / \mathrm{dL}$, an age-adjusted value not different from that observed in the normal population.

Thrombocytopenia was present in 184 patients at baseline. Mean platelet count was $80.6 \pm 25.61 \times 10^{9} / \mathrm{L}$ and improved to a mean of $152.9 \pm 58.98 \times 10^{9} / \mathrm{L}$ after 4 years of treatment (Figure 2). This level of platelets was maintained, with some fluctuations, over 8 years of treatment.

Hepatomegaly and splenomegaly are commonly reported by means of palpation in Latin America. For this reason, qualitative assessments of visceromegaly are included. Among the 204 patients with qualitative hepatomegaly at baseline, 127 patients (62.3\%) improved at their most recent follow-up. Similarly, among the 204 patients with qualitative splenomegaly at baseline, 109 patients (53.4\%) improved at their most recent follow-up.
Hepatomegaly using volumetric measures was reported in 19 patients at baseline. Liver size decreased dramatically from baseline (mean $2.1 \pm 0.65 \mathrm{MN}$ ) through the first year (mean $1.5 \pm 0.36 \mathrm{MN}$ ) of treatment (Figure 3). Liver size continued to decrease slowly throughout the 8-year treatment period and reached a mean of $0.9 \pm 0.09 \mathrm{MN}$.

Using volumetric evaluations, 33 patients reported splenomegaly at baseline with a mean spleen volume of 21.4 $\pm 9.98 \mathrm{MN}$ (Figure 4). After 3 years of treatment, a yearly decline in spleen volume was observed to $9.4 \pm 6.63 \mathrm{MN}$. This trend continued and reached $2.7 \pm 1.66 \mathrm{MN}$ after 8 years of treatment.

Imiglucerase treatment resulted in improved skeletal symptoms as noted by decreased bone pain and bone crises (Table 3 ). In those patients with available bone crisis data, only 24 reported bone crises prior to initiation of imiglucerase. Of these, no patients reported further bone crises during the first 6 years of treatment, and 1 patient reported an event after 6 years of treatment. A similar trend was observed for patients with available bone pain data. Of the 79 patients who reported bone pain prior to the start of imiglucerase, only 5 patients reported bone pain after 8 years of treatment.

Height Z-scores also improved with imiglucerase treatment (Figure 5) from a mean of $-2.3 \pm 1.11(n=129)$ at baseline to $-0.8 \pm 0.94(n=30)$ after 8 years of treatment.

\section{Discussion}

This study reports the clinical characteristics of 443 Latin American pediatric patients in the ICGG Gaucher Registry who received therapy with imiglucerase and demonstrates the clinical improvements seen in hematological, visceral, and skeletal manifestations of GD1 after longterm treatment.

Although most $(83.9 \%, 363 / 443)$ of the children in this study were diagnosed before 12 years of age, $43.6 \%$ $(190 / 443)$ of them were diagnosed before 6 years of age (Table 1). This is important to note because disease onset in early childhood is characterized by a faster progression and a more aggressive clinical course compared with adolescent-onset disease [6] and early treatment may prevent disease progression.

Common genotypes reported in this Latin American population of children included at least one N370S allele: N370S/Rare Allele, N370S/L444P and N370S/? (Table 1). It is possible that the predominance of the N370S allele reflects the large Brazilian population in this cohort. A previous study [21] reported N370S/L444P and N370S/Rare Allele as the most common genotypes in Brazil. The N370S mutation is associated with GD1, and other common GD1 mutations are L444P, 84GG and IVS2+ $[6,7,14,15]$. All of these mutations were reported in this cohort of children from Latin America, which is in 
A

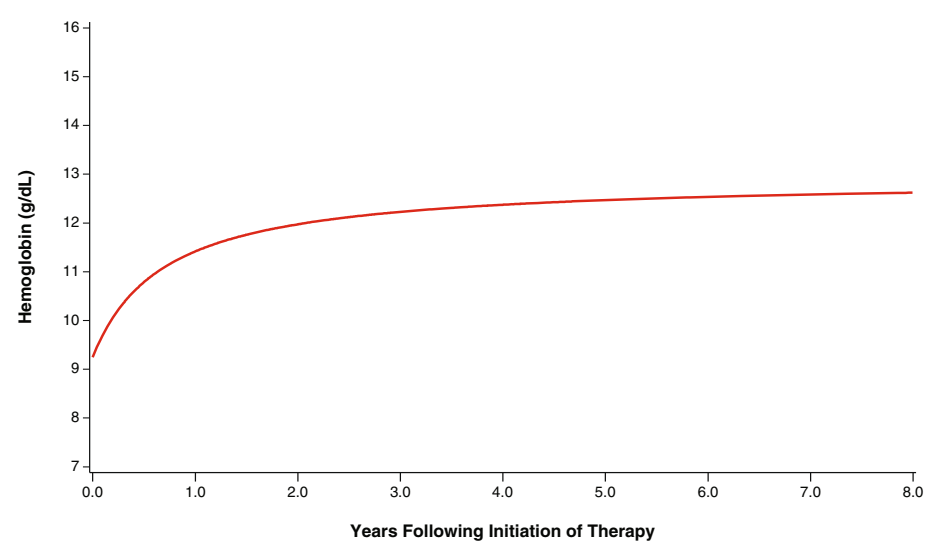

B

\begin{tabular}{|r|c|c|c|c|c|c|c|c|c|c|}
\hline Parameter & Statistic & Baseline & $>\mathbf{0}$ to $\leq 1$ & $>\mathbf{1}$ to $\leq \mathbf{2}$ & $>\mathbf{2}$ to $\leq \mathbf{3}$ & $>\mathbf{3}$ to $\leq \mathbf{4}$ & $>\mathbf{4}$ to $\leq \mathbf{5}$ & $\mathbf{> 5}$ to $\leq 6$ & $>\mathbf{6}$ to $\leq \mathbf{7}$ & $>\mathbf{7}$ to $\leq \mathbf{8}$ \\
\hline Hemoglobin (g/dL) & $\mathrm{n}$ & 174 & 153 & 134 & 123 & 110 & 99 & 77 & 67 & 63 \\
\hline & Mean (SD) & $9.2(1.29)$ & $11.1(1.59)$ & $11.7(1.21)$ & $12.1(1.37)$ & $12.2(1.25)$ & $12.3(1.32)$ & $12.4(1.58)$ & $12.4(1.60)$ & $12.8(1.51)$ \\
\cline { 2 - 12 }$y$ & Median & 9.4 & 11.3 & 11.6 & 12.0 & 12.1 & 12.0 & 11.9 & 12.3 & 12.6 \\
\cline { 2 - 12 } & Min, Max & $4.5,11.8$ & $5.1,15.1$ & $8.9,15.0$ & $7.6,17.0$ & $8.6,15.2$ & $7.7,15.9$ & $10.1,18.0$ & $6.8,16.5$ & $10.3,16.2$ \\
\cline { 2 - 10 }
\end{tabular}

Figure 1 Long-term hemoglobin responses for Latin American pediatric GD1 patients with anemia ${ }^{a}$ at baseline. The $\mathbf{A}$ part of the figure indicates nonlinear mixed models and the $\mathbf{B}$ part provides summary statistics. ${ }^{a}$ Anemia is defined according to age and gender norms for hemoglobin concentrations as follows: $<12 \mathrm{~g} / \mathrm{dL}$ for males older than 12 years; $<11 \mathrm{~g} / \mathrm{dL}$ for females older than 12 years; $<10.5 \mathrm{~g} / \mathrm{dL}$ for children ages $>2$ to 12 years; $<9.5 \mathrm{~g} / \mathrm{dL}$ for children ages 6 months to 2 years; $<10.1 \mathrm{~g} / \mathrm{dL}$ for children younger than 6 months of age.

agreement with a recent report on patients of all ages from this region [10].

Most children had symptoms across different parameters. In our cohort of symptomatic Latin American children at baseline, patients who were symptomatic within a given parameter demonstrated rapid improvement once regular imiglucerase therapy was started. Similarly, laboratory parameters returned to normal values within 8 years of therapy, but often sooner. The time course of this response was almost identical to that observed in a global

A

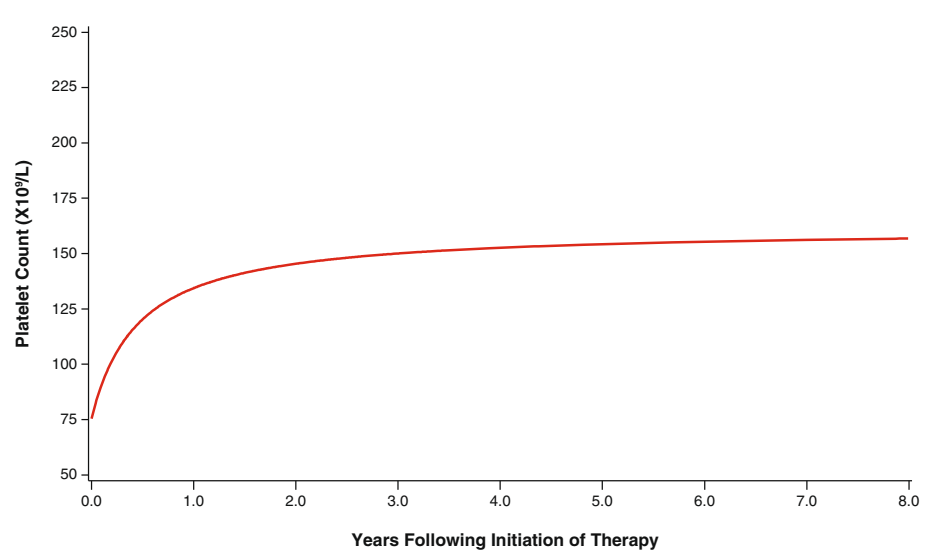

B

\begin{tabular}{|r|c|c|c|c|c|c|c|c|c|c|}
\hline Parameter & Statistic & Baseline & $>\mathbf{0}$ to $\leq 1$ & $>\mathbf{1}$ to $\leq \mathbf{2}$ & $\mathbf{> 2}$ to $\leq \mathbf{3}$ & $\mathbf{> 3}$ to $\leq \mathbf{4}$ & $\mathbf{> 4}$ to $\leq \mathbf{5}$ & $\mathbf{> 5}$ to $\leq \mathbf{6}$ & $>\mathbf{6}$ to $\leq \mathbf{7}$ & $>\mathbf{7}$ to $\leq \mathbf{8}$ \\
\hline Platelet Count & $\mathrm{n}$ & 184 & 158 & 146 & 130 & 115 & 96 & 75 & 75 & 69 \\
\hline & Mean (SD) & $80.6(25.61)$ & $120.3(65.55)$ & $146.6(68.27)$ & $145.8(63.14)$ & $152.9(58.98)$ & $155.5(57.34)$ & $154.5(53.63)$ & $149.4(48.37)$ & $151.7(58.95)$ \\
\cline { 2 - 11 } & Median & 83.5 & 113.5 & 140.5 & 144.5 & 156.0 & 152.5 & 161.0 & 154.0 & 155.0 \\
\cline { 2 - 11 } & Min, Max & $15.0,119.0$ & $19.4,450.0$ & $20.0,414.0$ & $30.0,340.0$ & $16.9,322.0$ & $40.0,290.0$ & $30.0,267.0$ & $40.0,262.0$ & $36.0,291.0$ \\
\hline
\end{tabular}

Figure 2 Long-term platelet responses for Latin American pediatric GD1 patients with thrombocytopenia ${ }^{a}$ at baseline. The $\mathbf{A}$ part of the figure indicates nonlinear mixed models and the $\mathbf{B}$ part provides summary statistics. ${ }^{a}$ Thrombocytopenia is defined as platelet count $<120 \times 10^{9} / \mathrm{L}$. 
A

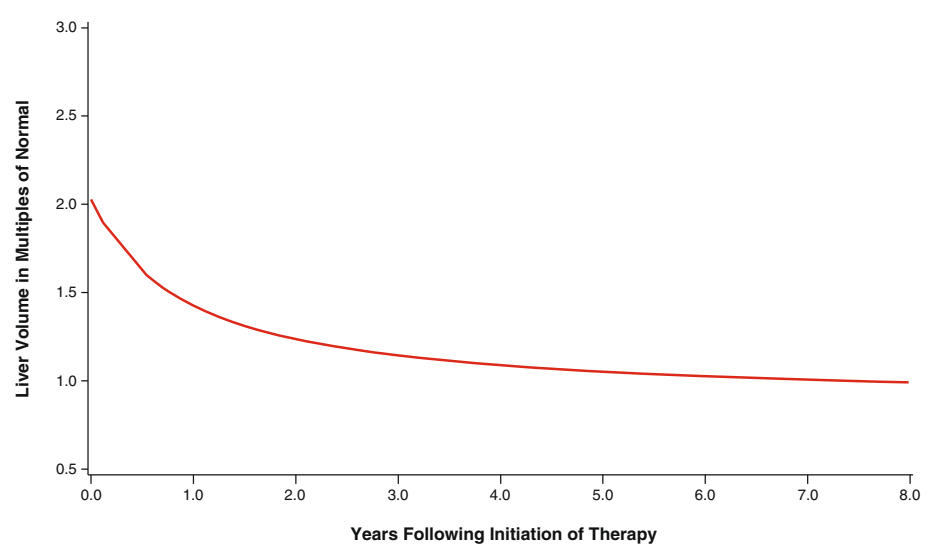

B

\begin{tabular}{|c|c|c|c|c|c|c|c|c|c|c|}
\hline Parameter & Statistic & Baseline & $>0$ to $\leq 1$ & $>1$ to $\leq 2$ & $>2$ to $\leq 3$ & $>3$ to $\leq 4$ & $>4$ to $\leq 5$ & $>5$ to $\leq 6$ & $>6$ to $\leq 7$ & $>7$ to $\leq 8$ \\
\hline \multirow[t]{4}{*}{$\begin{array}{r}\text { Liver Volume in } \\
\text { Multiples of Normal }\end{array}$} & $\mathrm{n}$ & 19 & 8 & 10 & 10 & 3 & 8 & 5 & 4 & 4 \\
\hline & Mean (SD) & $2.1(0.65)$ & $1.5(0.36)$ & $1.4(0.30)$ & $1.2(0.29)$ & $1.2(0.05)$ & $1.1(0.22)$ & $1.0(0.16)$ & $1.0(0.07)$ & $0.9(0.09)$ \\
\hline & Median & 1.9 & 1.4 & 1.4 & 1.2 & 1.2 & 1.1 & 1.0 & 1.0 & 0.9 \\
\hline & Min, Max & $1.4,4.1$ & $1.0,2.1$ & $0.9,2.0$ & $0.8,1.7$ & $1.1,1.2$ & $0.8,1.4$ & $0.8,1.2$ & $0.9,1.1$ & $0.8,1.0$ \\
\hline
\end{tabular}

Figure 3 Long-term liver volume responses for Latin American pediatric GD1 patients with hepatomegaly at baseline. The $\mathbf{A}$ part of the figure indicates nonlinear mixed models and the $\mathbf{B}$ part provides summary statistics. ${ }^{a}$ Hepatomegaly is defined as liver volumes $>1.25 \mathrm{MN}$.

population of children with GD1 [14], and was considered in the development of revised recommendations for the management of GD in children [22].

The improved hemoglobin and platelet levels may be due to reduction of Gaucher cells in the bone marrow as well as improvement in the hypersplenic state. Although consistent with other data that demonstrates reduction of spleen volume over the years on imiglucerase therapy in children [14] and adults [15], the improvement seen in this cohort is driven by qualitative measurements, given the small number of volumetric spleen measurements reported to the ICGG Gaucher Registry from Latin America $(\mathrm{n}=33$ at baseline, $\mathrm{n}=4$ at year 8$)$.

Growth retardation in childhood and delayed puberty are characteristics of GD1 and are more frequent with severe disease. In the current report, 129 children with

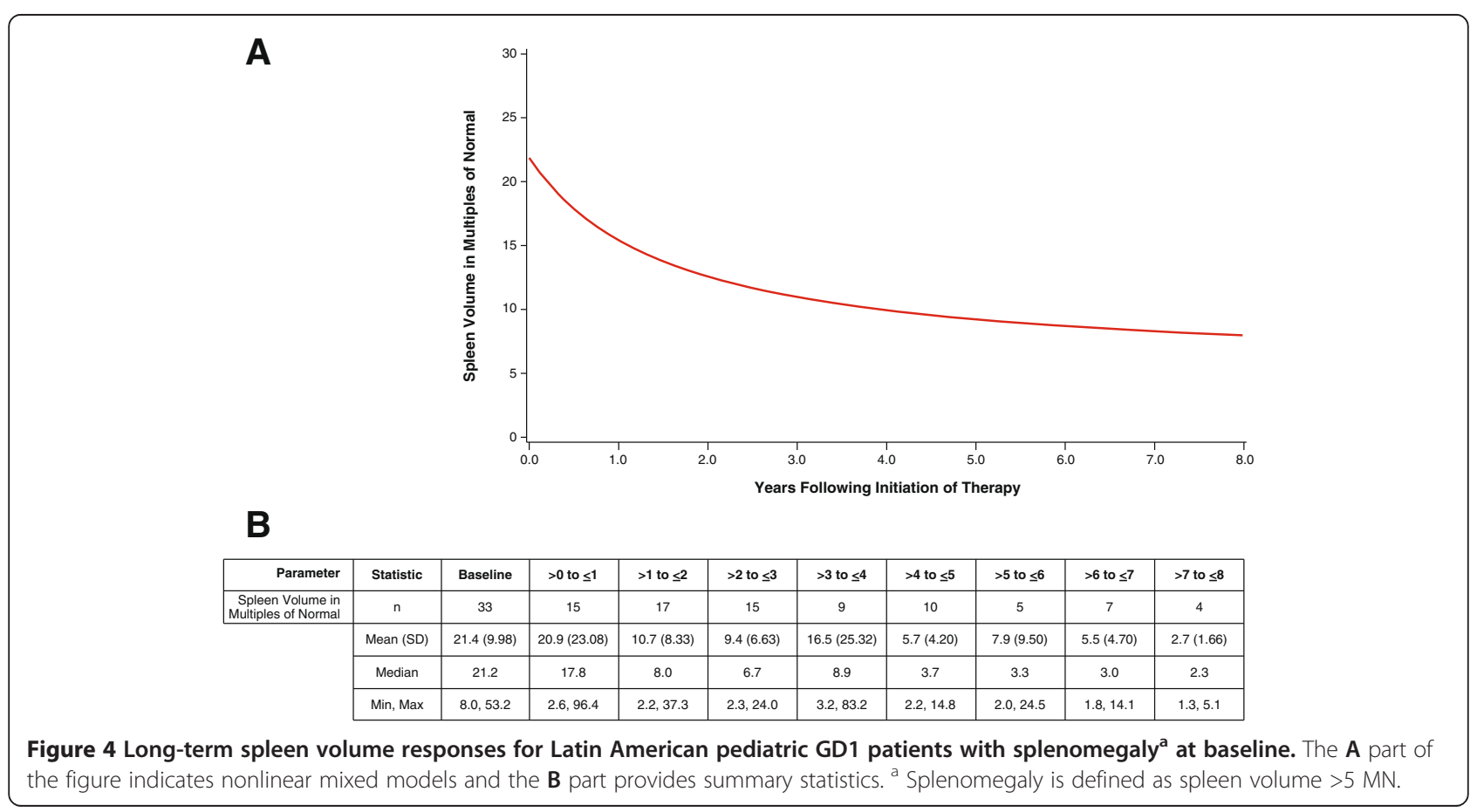


A

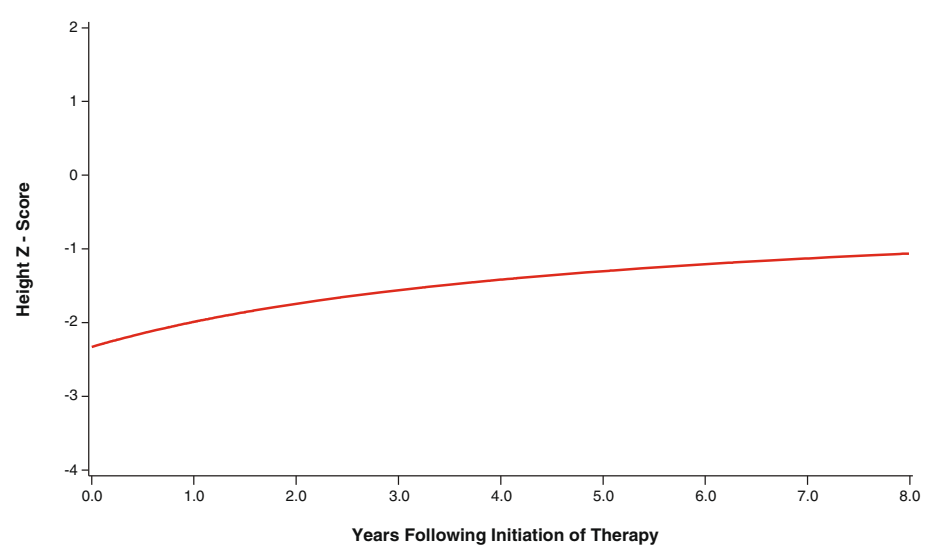

B

\begin{tabular}{|r|c|c|c|c|c|c|c|c|c|c|}
\hline Parameter & Statistic & Baseline & $>\mathbf{0}$ to $\leq 1$ & $>\mathbf{1}$ to $\leq \mathbf{2}$ & $\mathbf{> 2}$ to $\leq \mathbf{3}$ & $>\mathbf{3}$ to $\leq 4$ & $>\mathbf{4}$ to $\leq 5$ & $>\mathbf{5}$ to $\leq 6$ & $>\mathbf{6}$ to $\leq 7$ & $>\mathbf{7}$ to $\leq \mathbf{8}$ \\
\hline Height Z-score & $\mathrm{n}$ & 129 & 99 & 91 & 88 & 72 & 65 & 54 & 46 & 30 \\
\hline & Mean (SD) & $-2.3(1.11)$ & $-2.1(1.23)$ & $-1.8(1.24)$ & $-1.7(1.21)$ & $-1.6(1.17)$ & $-1.6(1.23)$ & $-1.2(1.14)$ & $-1.2(1.18)$ & $-0.8(0.94)$ \\
\cline { 2 - 11 } & Median & -2.1 & -2.0 & -1.8 & -1.7 & -1.5 & -1.5 & -1.2 & -1.0 & -0.8 \\
\cline { 2 - 11 } & Min, Max & $-6.1,-1.0$ & $-5.9,1.2$ & $-5.5,1.8$ & $-4.8,1.6$ & $-4.9,0.7$ & $-5.2,0.7$ & $-4.5,1.0$ & $-4.6,0.7$ & $-2.6,1.3$ \\
\cline { 2 - 10 }
\end{tabular}

Figure 5 Long-term height Z-score responses for Latin American pediatric GD1 patients with growth retardation ${ }^{\mathrm{a}}$ at baseline. The $\mathbf{A}$

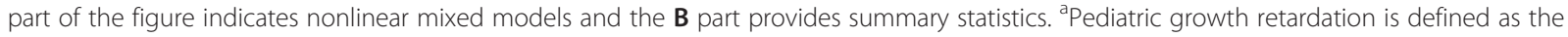
number of patients who are below the 5th percentile for height based on age and gender of the normal healthy population and is calculated as $0.05 \times$ the total number of patients.

growth retardation had height Z-scores at baseline. With imiglucerase treatment, height Z-score improved. A previous study [23] and case report [24] suggest that the growth and puberty delay could be related to impaired production of insulin-like growth factor-1 by the liver of GD1 patients. Enzyme therapy can decrease liver size, potentially improving its function and normalizing growth factor-1 production, thus contributing to the observed improvements in growth.

Table 3 Long-term bone crisis and bone pain responses for all symptomatic pediatric GD1 patients at baseline ${ }^{a}$

\begin{tabular}{llllll}
\hline Years on imiglucerase & \multicolumn{2}{l}{ Bone crisis, $\mathbf{n}(\%)$} & & \multicolumn{2}{l}{ Bone pain, $\mathbf{n}(\%)$} \\
\cline { 2 - 3 } \cline { 5 - 6 } & Yes & No & & Yes & No \\
\hline Baseline, $N$ & $N=24$ & $N=0$ & & $N=79$ & $N=0$ \\
$>0-\leq 1$ & $0(0.0)$ & $5(100.0)$ & & $2(18.2)$ & $9(81.8)$ \\
$>1-\leq 2$ & $0(0.0)$ & $1(100.0)$ & & $1(33.3)$ & $2(66.7)$ \\
$>2-\leq 3$ & $0(0.0)$ & $3(100.0)$ & & $0(0.0)$ & $5(100.0)$ \\
$>3-\leq 4$ & $0(0.0)$ & $0(0.0)$ & & $2(40.0)$ & $3(60.0)$ \\
$>4-\leq 5$ & $0(0.0)$ & $2(100.0)$ & & $1(14.3)$ & $6(85.7)$ \\
$>5-\leq 6$ & $0(0.0)$ & $0(0.0)$ & & $0(0.0)$ & $10(100.0)$ \\
$>6-\leq 7$ & $1(33.3)$ & $2(66.7)$ & & $2(28.6)$ & $5(71.4)$ \\
$>7-\leq 8$ & $0(0.0)$ & $10(100.0)$ & $5(16.1)$ & $26(83.9)$ \\
\hline
\end{tabular}

a'Baseline' is defined as the data point closest to the first infusion date, at all time prior to through 2 weeks (inclusive) following first infusion. Patients with no infusion date were excluded from the analysis.
Bone crisis and bone pain were two skeletal manifestations that showed steady improvements after initiation of therapy with imiglucerase. Twenty-four patients reported bone crisis before initiating imiglucerase; within 1 year, none reported an event after imiglucerase therapy (Table 3). Seventy-nine patients in our Latin American cohort reported pre-treatment bone pain data; after 8 years of imiglucerase treatment, $83.9 \%$ of patients were symptom-free. Such improvements in bone pain and bone crisis have been reported previously [13]. Taken together, our findings indicate a substantial skeletal benefit from imiglucerase treatment in Latin American pediatric patients with GD1.

The skeletal effect of imiglucerase has been documented with bone mineral density analysis using dual energy $x$-ray absorptiometry $[14,25,26]$. Given that the "critical peak" bone mass is accumulated within the first two decades of life [27], and that pediatric-onset GD1 is characterized by a fast, aggressive progression [14,22], these authors suggest early initiation of imiglucerase therapy for symptomatic children with GD.

Large population-based studies are only possible with data provided from large cohorts of patients, such as that in the ICGG Gaucher Registry. There are, however, some limitations to analyses from the ICGG Gaucher Registry. Data are not submitted at well-defined time points, and disease severity at baseline and treatment effects vary by patient. All Registry data are retrospective. Patients followed in the Registry are not randomized to 
treatment with imiglucerase. The type of GD is physician-reported and the method of genotyping, if available, is not recorded in the Registry. In Latin America, there is less access to visceral volumetric evaluations and densitometries as well as assessment of bone mineral density by dual energy $\mathrm{x}$-ray absorptiometry, which accounts for the sparse data in this report. In contrast, Latin American physicians commonly determine organ involvement by palpation [10], which is why it was included in this report. Other confounding factors include epigenetic and environmental factors. These limitations are common to global observational research studies.

The data from this report are consistent with other data in children [14] and adults [15] which indicated that most clinical manifestations in patients with GD improved once regular treatment with imiglucerase was initiated. The time course of this response in previous reports was almost identical to those observed in our cohort of symptomatic Latin American children. Additionally, and importantly, continued therapy is key, since the potential benefits of imiglucerase may be reversed when treatment is withdrawn, and relapses have been documented [28-30].

\section{Conclusion}

Continuous and long-term imiglucerase therapy improves hematological, visceral and skeletal symptoms, and reverses most of the clinical and biochemical manifestations of GD1 in children from Latin America.

\section{Abbreviations \\ GD: Gaucher disease; GD1: Gaucher disease type 1; g/dL: gram/deciliter; ICGG: International Collaborative Gaucher Group; L: liter; MN: Multiples of Normal; SD: Standard Deviation; USA: United States of America.}

\section{Competing interests}

Financial competing interests. Adriana Linares declares that she has no competing interests. Jose Simon Camelo Jr: works full time at the University of São Paulo, participates in the ICGG Gaucher Registry and receives fees from Genzyme, a Sanofi company for lectures and educational activities. Juan Francisco Cabello is a member of the ICGG Gaucher Registry Latin American Board and does not receive any fees for this work. Guillermo G. Drelichman is a member of the ICGG Gaucher Registry Latin American Board and receives fees from Genzyme, a Sanofi company as a lecturer and for educational activities. Andrea R. Gwosdow is a professional medical writer supported by Genzyme, a Sanofi company to prepare the manuscript. Marcelo M. Kerstenetzky is a member of the ICGG Gaucher Registry Latin American Board and receives fees from Genzyme, a Sanofi company as the Registry coordinator for Brazil, for lectures and educational activities. Soledad Suarez Ordoñez is a contractor employed by Genzyme Latin America, a Sanofi company. Isabel C. Sarmiento is a member of the ICGG Gaucher Registry Latin American Board and receives fees from Genzyme as the Registry coordinator for Colombia. John S. Taylor is an employee of Genzyme, a Sanofi company.

\section{Authors' contributions}

AL participated in study's conception and design, conceived the idea for the article, analyzed published literature, and critically reviewed the manuscript. SSO conceived the idea for the article, interpreted the data, and critically reviewed the manuscript. JSCJ participated in study's conception and design, interpreted the data, analyzed the published literature, and critically reviewed the manuscript. JST conducted/managed the study, collected the data, performed the statistical analysis, interpreted the data, and critically reviewed the manuscript. ARG interpreted the data, analyzed the published literature, drafted the manuscript, and critically reviewed the manuscript. IS interpreted the data, analyzed the published literature and critically reviewed the manuscript. MMK and JFC interpreted the data and critically reviewed the manuscript. GGD interpreted the data, analyzed the published literature and critically reviewed the manuscript. All authors read and approved the final manuscript.

\section{Acknowledgments}

We would like to thank all patients with Gaucher disease and their physicians and health care personnel who submit data to the ICGG Gaucher Registry, the Gaucher Registry support team at Genzyme, a Sanofi company, Alfred Mbah and J Alexander Cole for help with statistical analyses, Cherie Dewar for help formatting the manuscript, Brian DelGiudice and Robert Brown for preparing the figures.

This manuscript's funding source and logistical support were provided by Genzyme, a Sanofi company. The funding source for Andrea R. Gwosdow, Soledad Suarez Ordoñez and John S. Taylor is Genzyme, a Sanofi company. Name of institution or service with which the work is associated for indexing in Index Medicus/Medline: ICGG Gaucher Registry.

\section{Author details}

${ }^{1}$ Departamento de Puericultura e Pediatria, Faculdade de Medicina de Ribeirão Preto, Universidade de São Paulo, São Paulo, Brasil. 'Laboratorio de Genética y Enfermedades Metabólicas. INTA, Universidad de Chile, Santiago, Chile. ${ }^{3}$ Servicio de Hematología, Hospital de Niños Ricardo Guitiérrez, Buenos Aires, Argentina. ${ }^{4}$ Instituto de Medicina Integral Professor Fernando Figueira (IMIP), Recife, Pernambuco, Brasil. ${ }^{5}$ Oncohematóloga Pediatria, Fundación Hospital de la Misericordia, Bogotá, Colombia. ${ }^{6}$ Genzyme Latin America, a Sanofi company, Buenos Aires, Argentina. ${ }^{7}$ Strategic Epidemiology, Genzyme, a Sanofi company, Cambridge, MA, USA. ${ }^{8}$ Genzyme PGH Registries, Genzyme, a Sanofi company, Cambridge, MA, USA. ${ }^{9}$ Pediatrics, Universidad Nacional de Colombia, Calle 50 8-24 of 401, Bogotá, Colombia.

Received: 17 December 2013 Accepted: 1 July 2014

Published: 11 July 2014

\section{References}

1. Brady RO, Kanfer JN, Shapiro D: Metabolism of Glucocerebrosides. II. Evidence of an Enzymatic Deficiency in Gaucher's Disease. Biochem Biophys Res Commun 1965, 18:221-225.

2. Grabowski GA, Kolodny EH, Weinreb NJ, Rosenbloom BE, Prakash-Cheng A, Kaplan P, Charrow J, Pastores GM, Mistry PK: Gaucher Disease: Phenotypic and Genetic Variation. In OMMBID - The Online Metabolic and Molecular Bases of Inherited Diseases. Edited by Valle D, Beaudet AL, Vogelstein B, Kinzler KW, Antonarakis SE, Ballabio A, Gibson K, Mitchell G. New York, NY: McGraw-Hill; 2014. http://ommbid.mhmedical.com/content.aspx?book$i d=474 \&$ Sectionid=45374149. Accessed July 09, 2014.

3. Brady RO: Gaucher's disease: past, present and future. Baillieres Clin Haematol 1997, 10(4):621-634.

4. Grabowski GA: Phenotype, diagnosis, and treatment of Gaucher's disease. Lancet 2008, 372(9645):1263-1271.

5. Elstein D, Abrahamov A, Dweck A, Hadas-Halpern I, Zimran A: Gaucher disease: pediatric concerns. Paediatr Drugs 2002, 4(7):417-426.

6. Kaplan P, Andersson HC, Kacena KA, Yee JD: The clinical and demographic characteristics of nonneuronopathic Gaucher disease in 887 children at diagnosis. Arch Pediatr Adolesc Med 2006, 160(6):603-608.

7. Charrow J, Andersson HC, Kaplan P, Kolodny EH, Mistry P, Pastores G, Rosenbloom BE, Scott CR, Wappner RS, Weinreb NJ, Zimran A: The Gaucher Registry: demographics and disease characteristics of 1698 patients with Gaucher disease. Arch Intern Med 2000, 160(18):2835-2843.

8. Zevin S, Abrahamov A, Hadas-Halpern I, Kannai R, Levy-Lahad E, Horowitz M, Zimran A: Adult-type Gaucher disease in children: genetics, clinical features and enzyme replacement therapy. Q J Med 1993, 86(9):565-573.

9. Kauli R, Zaizov R, Lazar L, Pertzelan A, Laron Z, Galatzer A, Phillip M, Yaniv Y, Cohen IJ: Delayed growth and puberty in patients with Gaucher disease type 1: natural history and effect of splenectomy and/or enzyme replacement therapy. Isr Med Assoc J 2000, 2(2):158-163.

10. Drelichman G, Linares A, Villalobos J, Cabello JF, Kerstenetzky M, Kohan RM, Martins AM: Gaucher disease in Latin America. A report from the Gaucher Disease International Registry and the Latin American Group for Gaucher Disease. Medicina (B Aires) 2012, 72(4):273-282. 
11. Grabowski GA, Barton NW, Pastores G, Dambrosia JM, Banerjee TK, McKee MA, Parker C, Schiffmann R, Hill SC, Brady RO: Enzyme therapy in type 1 Gaucher disease: comparative efficacy of mannose-terminated glucocerebrosidase from natural and recombinant sources. Ann Intern Med 1995, 122(1):33-39.

12. Weinreb NJ, Charrow J, Andersson HC, Kaplan P, Kolodny EH, Mistry P, Pastores G, Rosenbloom BE, Scott CR, Wappner RS, Zimran A: Effectiveness of enzyme replacement therapy in 1028 patients with type 1 Gaucher disease after 2 to 5 years of treatment: a report from the Gaucher Registry. Am J Med 2002, 113(2):112-119.

13. Charrow J, Dulisse B, Grabowski GA, Weinreb NJ: The effect of enzyme replacement therapy on bone crisis and bone pain in patients with type 1 Gaucher disease. Clin Genet 2007, 71(3):205-211.

14. Andersson H, Kaplan P, Kacena K, Yee J: Eight-year clinical outcomes of long-term enzyme replacement therapy for 884 children with Gaucher disease type 1. Pediatrics 2008, 122(6):1182-1190.

15. Weinreb NJ, Goldblatt J, Villalobos J, Charrow J, Cole JA, Kerstenetzky M, vom Dahl S, Hollak C: Long-term clinical outcomes in type 1 Gaucher disease following 10 years of imiglucerase treatment. $J$ Inherit Metab Dis 2012, 36(3):543-553.

16. Ludwig J: Current Methods of Autopsy Practice. 2nd edition. Philadelphia: Saunders; 1979

17. Elstein D, Hadas-Halpern I, Azuri Y, Abrahamov A, Bar-Ziv Y, Zimran A: Accuracy of ultrasonography in assessing spleen and liver size in patients with Gaucher disease: comparison to computed tomographic measurements. J Ultrasound Med 1997, 16(3):209-211.

18. Kuczmarski RJ, Ogden CL, Grummer-Strawn LM, Flegal KM, Guo SS, Wei R, Mei Z, Curtin LR, Roche AF, Johnson CL: CDC growth charts: United States. Adv Data 2000, 314:1-27.

19. Davidian M, Giltinan DM: Some general estimation methods for nonlinear mixed-effects models. J Biopharm Stat 1993, 3(1):23-55.

20. von Elm E, Altman DG, Egger M, Pocock SJ, Gøtzsche PC, Vandenbroucke JP, STROBE Initiative: The Strengthening the Reporting of Observational Studies in Epidemiology (STROBE) statement: guidelines for reporting observational studies. J Clin Epidemio/ 2008, 61(4):344-349.

21. Sobreira E, Pires RF, Cizmarik M, Grabowski GA: Phenotypic and genotypic heterogeneity in Gaucher disease type 1: a comparison between Brazil and the rest of the world. Mol Genet Metab 2007, 90(1):81-86.

22. Kaplan P, Baris H, De Meirleir L, Di Rocco M, El-Beshlawy A, Huemer M, Martins AM, Nascu I, Rohrbach M, Steinbach L, Cohen IJ: Revised recommendations for the management of Gaucher disease in children. Eur J Pediatr 2013, 172(4):447-458.

23. Rite S, Baldellou A, Giraldo P, Labarta Jl, Giralt M, Rubio-Felix D, Guallar A, Perez-Calvo Jl, Mayayo E, Ferrandez A, Pocovi M: Insulin-like growth factors in childhood-onset Gaucher disease. Pediatr Res 2002, 52(1):109-112.

24. Biasucci G, Manfredi P: Pediatric Gaucher disease type I and mild growth hormone deficiency: a new feature? J Inherit Metab Dis 2010 33 Suppl 3:S51-S54.

25. Mistry PK, Weinreb NJ, Kaplan P, Cole JA, Gwosdow AR, Hangartner T: Osteopenia in Gaucher disease develops early in life: response to imiglucerase enzyme therapy in children, adolescents and adults. Blood Cells Mol Dis 2011, 46(1):66-72.

26. Wenstrup RJ, Kacena KA, Kaplan P, Pastores GM, Prakash-Cheng A, Zimran A, Hangartner TN: Effect of enzyme replacement therapy with imiglucerase on BMD in type 1 Gaucher disease. J Bone Miner Res 2007, 22(1):119-126.

27. Bonjour JP, Theintz G, Buchs B, Slosman D, Rizzoli R: Critical years and stages of puberty for spinal and femoral bone mass accumulation during adolescence. J Clin Endocrinol Metab 1991, 73(3):555-563.

28. Toth J, Erdos M, Marodi L: Rebound hepatosplenomegaly in type 1 Gaucher disease. Eur J Haematol 2003, 70(2):125-128.

29. Grinzaid KA, Geller E, Hanna SL, Elsas LJ 2nd: Cessation of enzyme replacement therapy in Gaucher disease. Genet Med 2002, 4(6):427-433.

30. Drelichman G, Ponce E, Basack N, Freigeiro D, Aversa L, Graciela E, Kohan R: Clinical consequences of interrupting enzyme replacement therapy in children with type 1 Gaucher disease. J Pediatr 2007, 151(2):197-201.

doi:10.1186/2052-1839-14-10

Cite this article as: Camelo et al:: Long-term effect of imiglucerase in Latin American children with Gaucher disease type 1: lessons from the International Collaborative Gaucher Group Gaucher Registry. BMC Hematology 2014 14:10.

\section{Submit your next manuscript to BioMed Central and take full advantage of:}

- Convenient online submission

- Thorough peer review

- No space constraints or color figure charges

- Immediate publication on acceptance

- Inclusion in PubMed, CAS, Scopus and Google Scholar

- Research which is freely available for redistribution 